\title{
Influence of Particle Size on the Properties of Pt-Ru/C Catalysts Prepared by a Microemulsion Method
}

\author{
Denis R. M. Godoi, Joelma Perez, and H. Mercedes Villullas*,z \\ Departamento de Físico Química, Instituto de Química, Universidade Estadual Paulista (UNESP),
} 14801-970 CP 355, Araraquara (SP), Brazil

\begin{abstract}
$\mathrm{Pt}-\mathrm{Ru} / \mathrm{C}$ nanocatalysts were prepared by a microemulsion method using different values of water/surfactant molar ratio in order to get different particle sizes. Crystallite sizes and structural properties were determined by X-ray diffraction. Particle size and distribution were characterized by transmission electron microscopy and average composition was determined by energydispersive X-ray analysis. Thermogravimetric analysis was used to estimate the amount of supported metals. Differential scanning calorimetry measurements indicated the presence of hydrous ruthenium oxides in the as-prepared catalysts. Results for the oxidation of adsorbed $\mathrm{CO}$ as well as for methanol oxidation revealed significant differences in the behavior of the prepared catalysts. All together, the results demonstrate that the variation of particle size produces changes in other properties of the $\mathrm{Pt}-\mathrm{Ru} / \mathrm{C}$ catalysts and that to establish direct correlations between electrocatalytic activity and particle size is not possible because the effects of the different parameters cannot be separated.
\end{abstract}

(c) 2007 The Electrochemical Society. [DOI: 10.1149/1.2713689] All rights reserved.

Manuscript submitted December 11, 2006; revised manuscript received January 16, 2007.

Available electronically March 22, 2007.

The development of electrocatalysts for proton exchange membrane fuel cells (PEMFCs) is the subject of an increasing amount of research work. The conversion of chemical energy into electricity in direct methanol fuel cells (DMFCs) requires materials with higher catalytic activities to improve the performance of the anodes that is required to achieve current densities adequate for practical applications. Despite the great deal of effort devoted to the search for new electrocatalysts, $\mathrm{Pt}-\mathrm{Ru}$ is still the most active anode material for methanol electro-oxidation.

Several methods have been used for the preparation of carbonsupported Pt and Pt-Ru catalysts. ${ }^{1-6}$ The most relevant methods to prepare Pt-Ru catalysts were reviewed recently. ${ }^{7}$ Published results clearly show that electrocatalytic activity is significantly influenced by a number of physical properties of the catalysts, such as composition, structure, morphology, particle size, and degree of alloying. It has also been shown that those properties depend on the synthesis conditions and, therefore, it is not surprising to find that the electrocatalytic activity is also strongly dependent on the preparation methodology adopted.

Despite the fact that $\mathrm{Pt}-\mathrm{Ru} / \mathrm{C}$ catalysts have been prepared in a number of different ways, impregnation methods are the most widely employed. ${ }^{8-13}$ When preparing bimetallic particles by impregnation, to control the catalyst composition may be difficult because the active components of the catalysts may deposit on different sites of the support. However, the major drawback of impregnation methods is still the difficulty in controlling nanoparticle size and distribution. The properties of the support, such as its morphology, seem to affect the structure and size of the metal particles. For instance, significant differences in particle size have been reported for $\mathrm{Pt}$ and $\mathrm{Pt}-\mathrm{Ru}$ catalysts prepared by the impregnation technique on single-wall and multiwall carbon nanotubes and on a high surface area carbon powder (Vulcan XC-72). ${ }^{14}$ Similarly, Hills et al. ${ }^{15}$ prepared nanoparticles of either Pt or Ru onto different carbon supports, Vulcan XC-72 and Shawinigan acetylene black, and observed that smaller particles were obtained for the Vulcansupported samples, concluding that the carbon supports appear to influence the growth properties of the homometallic clusters. Also, it has been reported that chemical treatments to functionalize Vulcan $\mathrm{XC}-72 \mathrm{R}$ affect to a significant extent the activity of Pt-Ru catalysts prepared by impregnation with solution of $\mathrm{H}_{2} \mathrm{PtCl}_{6}$ and $\mathrm{RuCl}_{3}$ precursors and reduced with formaldehyde. ${ }^{16}$

An alternative to overcome these problems is to prepare the metal nanoparticles in a colloidal state and subsequently deposit

\footnotetext{
* Electrochemical Society Active Member.

zz-mail: mercedes@iq.unesp.br
}

them on the support material. The main advantage of this kind of procedure is that particle properties should, in principle, be independent of the support. Among other methods, the synthesis in microemulsions has attracted considerable attention as a way of obtaining small nanoparticles with very narrow size distribution, and it has been used to prepare several metallic and bimetallic colloidal systems, including Pt-based bimetallic nanoparticles. ${ }^{17}$ The claimed advantages of the method are the ease of controlling metallic composition and particle size. Also, it is frequently pointed out that because of the structural characteristics of the microemulsions it should be possible to obtain nanoparticles of controlled size and with a narrow size distribution by varying the synthesis conditions that determine the size of the reverse micelles. There are two main approaches to obtain nanoparticles from microemulsions: by mixing two microemulsions, one that contains the metal precursors and the other the reducing agent, or by direct addition of the reducer to the microemulsion containing the metal precursors. In either case, the reduction reaction would be confined to the interior of the nanometric micelles, and thus, the sizes of the metal particles formed should be easily controlled by the dimensions of the water droplet, which, in turn, can be controlled by various parameters, in particular, by the water/surfactant molar ratio $(w) .{ }^{18}$

To the best of our knowledge, only six papers have reported studies of electrocatalytic properties of $\mathrm{Pt}-\mathrm{Ru}$ nanoparticles prepared in microemulsion systems for methanol oxidation. ${ }^{19-24}$ Different surfactants and oil phases and various conditions, such as one ${ }^{22,24}$ or two microemulsions, ${ }^{19-21,24}$ were employed. In only two cases catalyst compositions other than Pt-Ru 1:1 were studied, ${ }^{22,24}$ and only twice were supports other than high surface carbon powders used. ${ }^{21,22}$ In those studies where the water/surfactant molar ratio was kept constant, nearly monodispersed particles were obtained. ${ }^{19,20,22}$ In just one work, the concentration of the metal precursors in the aqueous phase was varied while keeping a constant $w$ value, being observed that particle size was a function of precursor concentration. ${ }^{21}$ Significant differences in particle size and other properties such as the onset potential for methanol oxidation were observed depending on preparation route (precursors initially in the same or in separate microemulsions) with all other variables kept identical. ${ }^{24}$ Only one study involved a systematic variation of the water pool dimensions by using different values of $w$, which resulted in Pt-Ru nanoparticles of different sizes. ${ }^{23}$ To the best of our knowledge, that is the only published paper dealing with the oxidation of methanol on Pt-Ru/C catalysts with different particle sizes. A maximum mass activity for methanol oxidation was reported for particle size of $5.3 \mathrm{~nm}$. Because all catalysts were prepared in the same manner, i.e., varying only the $w$ value in the microemulsion, 
the authors interpreted the different electrocatalytic activities that they observed as associated to particle size effects. ${ }^{23}$

In this work, $\mathrm{Pt}-\mathrm{Ru} / \mathrm{C}$ catalysts of different particle size were prepared by a microemulsion method, using different $w$ values. The physical properties of the catalysts were characterized by X-ray diffraction (XRD), transmission electron microscopy (TEM), energydispersive X-ray analysis (EDX), thermogravimetric analysis (TGA), and differential scanning calorimetry (DSC), and were found to vary with particle size. The electrochemical behavior in acid solutions and the catalytic activity for anodic methanol oxidation were evaluated by cyclic voltammetry (CV), linear sweep voltammetry (LSV), and chronoamperometry. In some cases, single fuel cell polarization measurements were also carried out. The whole set of data demonstrate that although all the catalysts studied were prepared by the same method, varying only the water/ surfactant molar ratio in order to obtain particles of different sizes, the differences in electrocatalytic activity toward methanol oxidation observed cannot be related solely to particle size effects.

\section{Experimental}

Electrocatalysts preparation.- $\mathrm{Pt}-\mathrm{Ru} / \mathrm{C}$ electrocatalysts were prepared by a reverse microemulsion method using dioctyl sulfosuccinate sodium salt (AOT) as surfactant and $n$-heptane as oil phase. The microemulsions were prepared by adding an aqueous solution of the precursors $\left(\mathrm{H}_{2} \mathrm{PtCl}_{6}\right.$ and $\left.\mathrm{RuCl}_{3}\right)$ to a mixture of $n$-heptane and AOT (15 wt \%) under constant stirring. The aqueous phase contained $0.5 \mathrm{wt} \%$ metal. The $\mathrm{Pt} / \mathrm{Ru}$ atomic ratio in the precursors solution was kept constant (1:1) while the water/AOT molar ratio (w) was varied from 4 to 10 . The reducing agent $\left(\mathrm{NaBH}_{4}\right)$ was added to the microemulsion as a solid in a molar ratio of 10:1 to metals. To ensure complete reduction the mixture was kept under constant stirring for $2 \mathrm{~h}$. In order to obtain the supported catalysts, an appropriate amount of high-surface-area carbon (Vulcan XC-72, Cabot) was then added to the mixture while kept in an ultrasonic bath. The suspension was then stirred overnight. All materials were $20 \%(\mathrm{w} / \mathrm{w})$ metal $(\mathrm{Pt}+\mathrm{Ru})$ on carbon. The supported catalysts thus formed were filtered, washed copiously with ethanol, acetone, and ultrapure water, and dried at $75^{\circ} \mathrm{C}$. Some samples were also subjected to heat-treatments at 250 and $450^{\circ} \mathrm{C}$ in hydrogen atmosphere. All reagents were purchased from Aldrich and used without further purification.

Electrocatalysts characterization.- The $\mathrm{Pt}-\mathrm{Ru} / \mathrm{C}$ catalysts were examined by XRD using a Rigaku model D Max 2500 PC diffractometer. The X-ray diffractograms were obtained with a scan rate of $2^{\circ} \mathrm{min}^{-1}$ and an incident wavelength of $0.15406 \mathrm{~nm}(\mathrm{Cu} \mathrm{K \alpha})$.

A Philips CM200 instrument operating at $200 \mathrm{kV}$, and equipped with EDS systems for energy-dispersive X-ray analysis, was used for the TEM study and EDX analysis.

TG analysis was performed on TA equipment model SDT Q600 in $\mathrm{O}_{2}\left(100 \mathrm{~mL} \mathrm{~min}^{-1}\right)$ or $\mathrm{N}_{2}\left(200 \mathrm{~mL} \mathrm{~min}^{-1}\right)$ with heating rate of

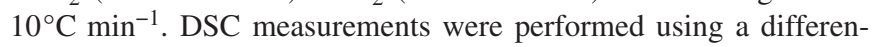
tial scanning calorimeter TA instrument model Q100, under $\mathrm{N}_{2}$ flux

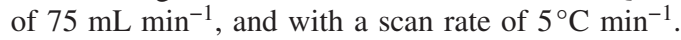

All the electrochemical measurements were done in a conventional electrochemical cell, with a Pt wire counter electrode placed in a separate compartment and a reversible hydrogen reference electrode. The $\mathrm{Pt}-\mathrm{Ru} / \mathrm{C}$ electrocatalysts were used as ultrathin layers ${ }^{25}$ on a glassy carbon disk electrode $\left(0.196 \mathrm{~cm}^{2}\right)$ previously polished down to $0.3 \mu \mathrm{m}$ alumina. In all cases, the catalyst layers had a metal loading of $28 \mu \mathrm{g} \mathrm{cm}^{-2}$. A drop of Nafion solution was applied on the catalyst to prevent loss of the powder.

Solutions were prepared from analytical-grade $\mathrm{H}_{2} \mathrm{SO}_{4}$ (Mallinckrodt), analytical-grade methanol (Mallinckrodt), and ultrapure water (MilliQ, Millipore).

The general electrochemical behavior was characterized by $\mathrm{CV}$ in $0.5 \mathrm{M} \mathrm{H}_{2} \mathrm{SO}_{4}$, and the electrocatalytic activity toward methanol

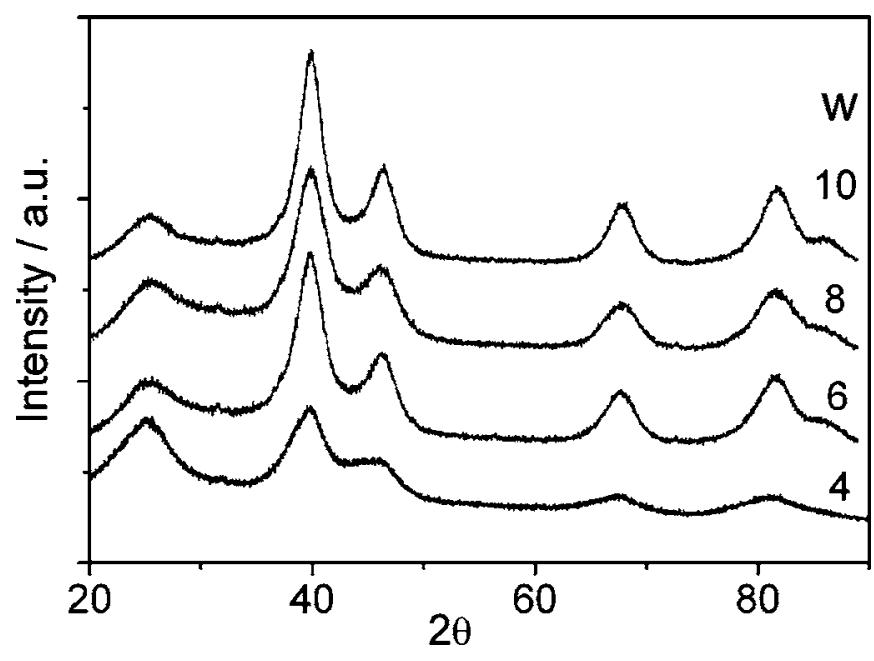

Figure 1. XRD patterns for the $\mathrm{Pt}-\mathrm{Ru} / \mathrm{C}$ catalysts obtained in microemulsions with different water/surfactant molar ratios $(w)$, as indicated.

oxidation was evaluated in $0.5 \mathrm{M}$ methanol acid solution by LSV and chronoamperometry. All experiments were done at $25^{\circ} \mathrm{C}$ in nitrogen-saturated solutions.

CO stripping experiments were carried out in the following way: After recording a $\mathrm{CV}$ in a $\mathrm{N}_{2}$-purged system, $\mathrm{CO}$ was admitted to the cell and adsorbed at $0.15 \mathrm{~V}$ vs RHE for $20 \mathrm{~min}$. The excess CO was eliminated with $\mathrm{N}_{2}$ gas, and the adsorbed $\mathrm{CO}$ was oxidized at a scan rate of $5 \mathrm{mV} \mathrm{s}^{-1}$.

For the fuel cell measurements, gas diffusion electrodes and membrane electrode assemblies (MEAs) were prepared as described by Paganin et al. ${ }^{26}$ The total metal loading of the catalysts layers was $1.0 \mathrm{mg} \mathrm{cm}^{-2}$ for both anode $(\mathrm{Pt}-\mathrm{Ru} / \mathrm{C})$ and cathode $(\mathrm{Pt} / \mathrm{C}$, $20 \mathrm{wt} \% \mathrm{E}-\mathrm{TEK})$. The fuel cell polarization curves were taken at $90^{\circ} \mathrm{C} / 3$ atm $\mathrm{O}_{2}$ pressure by circulating a $2 \mathrm{M}$ aqueous methanol solution at the anode.

\section{Results and Discussion}

Physical characterization.-TGA data were collected under flowing oxygen to eliminate the carbon by combustion, thus providing a qualitative measure of the metal loading of supported catalysts. Typically, TGA curves (not shown) presented an initial region involving a slight mass loss due to adsorbed water, followed by a second region where a gradual mass loss was observed from ca. 100 to $300^{\circ} \mathrm{C}$. In the third region, an abrupt mass loss commences at around $300^{\circ} \mathrm{C}$, and at temperatures of about $470^{\circ} \mathrm{C}$ all the carbon initially present was lost and the mass reached a constant value very close to the $20 \%$ nominal metal load. In a general manner, TGA curves were very similar to those reported by Baturina et al. ${ }^{27}$ for the thermal decomposition in air of $\mathrm{Pt} / \mathrm{C}$ samples. Even assuming complete oxidation of all the $\mathrm{Pt}$ and $\mathrm{Ru}$ in these catalysts to form $\mathrm{PtO}$ and $\mathrm{RuO}_{2}$, which would involve a mass gain of ca. $2 \%$ for the entire sample, the results obtained indicate that the metal loading was at least $18 \%$, which is in close agreement with the nominal value.

For all Pt-Ru/C electrocatalysts prepared, EDX analysis showed a $\mathrm{Pt} / \mathrm{Ru}$ ratio very close to the nominal composition $(1: 1)$.

The X-ray diffractograms obtained for $\mathrm{Pt}-\mathrm{Ru} / \mathrm{C}$ catalysts prepared in microemulsions of different $w$ values are shown in Fig. 1. For all the $\mathrm{Pt}-\mathrm{Ru} / \mathrm{C}$ electrocatalysts prepared, XRD showed diffraction patterns associated to the face-centered cubic (fcc) Pt structure (JCPDS 4-802). Scherrer's equation was used to calculate the mean crystallite size. For that, the [220] peak of the Pt fcc structure at $2 \theta \sim 67^{\circ}$ was used (because the broad carbon peak does not interfere in this region). The mean crystallite size was found to increase for increasing values of the water/surfactant molar ratio, as ex- 
pected. For all samples, the diffraction peaks are broad and slightly shifted toward higher $2 \theta$ values compared to those of Pt. Diffraction signals that could be associated with the presence of crystalline ruthenium or ruthenium oxides were not observed. The lattice parameter estimated from XRD data for the $\mathrm{Pt}-\mathrm{Ru} / \mathrm{C}$ catalysts is smaller than for Pt, in agreement with the expected contraction of the lattice due to the partial substitution of Pt by Ru in the fcc structure. ${ }^{28}$

The fraction of alloyed $\mathrm{Ru}$ in the $\mathrm{Pt}-\mathrm{Ru} / \mathrm{C}$ electrocatalysts was estimated assuming that the variation of lattice parameter on $\mathrm{Ru}$ content follows Vegard's law

$$
x_{(\mathrm{Ru})}=\frac{a-a_{\mathrm{o}}}{a_{\text {alloy }}-a_{\mathrm{o}}}
$$

where $a$ is the experimental value of lattice parameter for the $\mathrm{Pt}-\mathrm{Ru} / \mathrm{C}$ catalysts, $a_{\text {alloy }}$ is the lattice parameter for a $\mathrm{Pt}-\mathrm{Ru}$ solid solution of equiatomic composition taken here as $3.866 \AA,{ }^{29}$ and $a_{\text {o }}$ is the lattice parameter of supported Pt, $3.927 \AA$, that was determined for Pt/C samples and which value was found to be in good agreement with literature data. ${ }^{30}$

TEM images obtained for the $\mathrm{Pt}-\mathrm{Ru} / \mathrm{C}$ catalysts prepared by the microemulsion method showed in all cases, a narrow distribution of particle size and a highly uniform dispersion on the carbon support. Small aggregates were sporadically observed. A typical TEM photograph and a particle size distribution histogram are shown in Fig. 2 for an as-prepared $\mathrm{Pt}-\mathrm{Ru} / \mathrm{C}$ catalyst obtained in a microemulsion with $w=4$. Similar results, regarding uniform dispersion on the carbon support and narrow size distribution, were obtained for all catalysts prepared in this work. In general, the agreement between the XRD derived average crystallite sizes and mean particle sizes obtained from TEM images was quite good. The results obtained from the XRD and TEM studies are summarized in Table I.

While TEM data show that by changing the $w$ values in the microemulsion $\mathrm{Pt}-\mathrm{Ru} / \mathrm{C}$ catalysts with different average particle sizes were obtained, as expected, ${ }^{18}$ XRD data evidence that in addition to the change in particle size other properties, such as lattice parameter and $x(\mathrm{Ru})$, also varied. It must be noted that $x(\mathrm{Ru})$, as estimated by using Vegard's law, increases significantly with particle size, with the concomitant decrease in the lattice parameter. Moreover, the values of lattice constant and $x(\mathrm{Ru})$ indicate that in these $\mathrm{Pt}-\mathrm{Ru} / \mathrm{C}$ catalysts only part of the $\mathrm{Ru}$ present is actually alloyed with Pt. The presence of some segregated $\mathrm{Ru}$ is not a surprising result, as it seems to be the case for many Pt-Ru supported catalysts. ${ }^{7}$ However, it should be noted that the amount of $\mathrm{Ru}$ present as a separate phase would be larger for the smaller particles, indicating that the tendency to form an alloyed phase depends on particle size.

DSC measurements done in a $\mathrm{N}_{2}$ atmosphere showed that an initial endothermic loss occurs between ambient temperature and approximately $100^{\circ} \mathrm{C}$, followed by an exothermic transition that is completed at around $150^{\circ} \mathrm{C}$, as shown in Fig. 3. The curve obtained for the $\mathrm{Pt}-\mathrm{Ru} / \mathrm{C}$ catalyst prepared in a microemulsion with $w=4$ is almost identical to the one published by Rolison et al. ${ }^{31}$ for DSC measurements of hydrous ruthenium oxide, $\mathrm{RuO}_{2} \cdot x \mathrm{H}_{2} \mathrm{O}$. While the endothermic process is likely to be due to the removal of physisorbed water, the exothermic process has been previously interpreted as associated to a structural accommodation to the loss of water. $^{31}$ For the other three catalysts, the exothermic transition seems to involve two processes, one similar to that observed for the catalyst prepared with $w=4$, superimposed to a sharper signal identical to that observed for a $\mathrm{Pt} / \mathrm{C}$ catalyst under identical conditions (Fig. 3, insert). The definition of this second event increases with increasing $w$ values. In addition, TG analysis under a $\mathrm{N}_{2}$ flow showed a continuous loss of mass in the temperature range of the transitions observed in DSC experiments. Thus, any oxide species responsible for the processes observed during the DSC measurements were already present in the as-prepared catalysts and not formed during experiments.

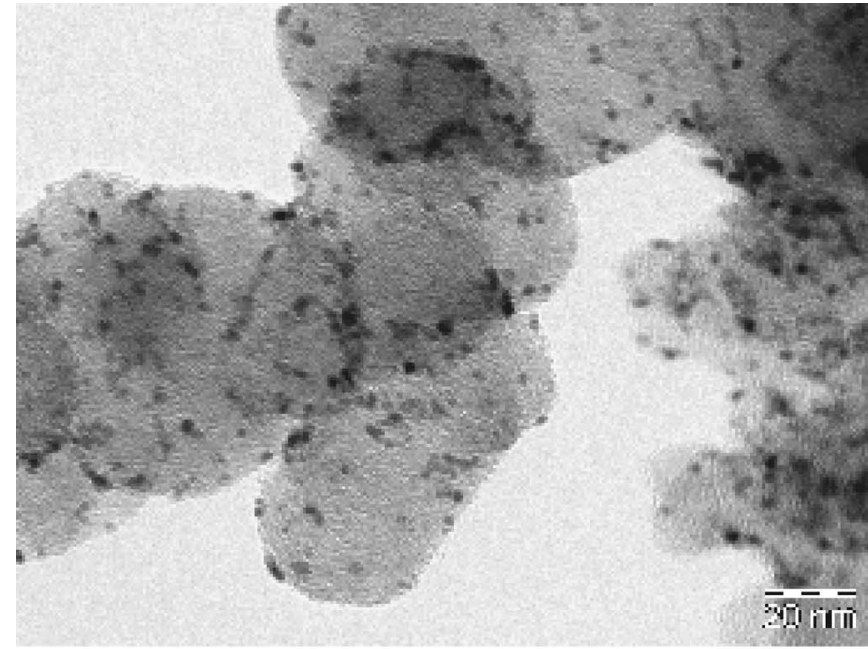

(a)

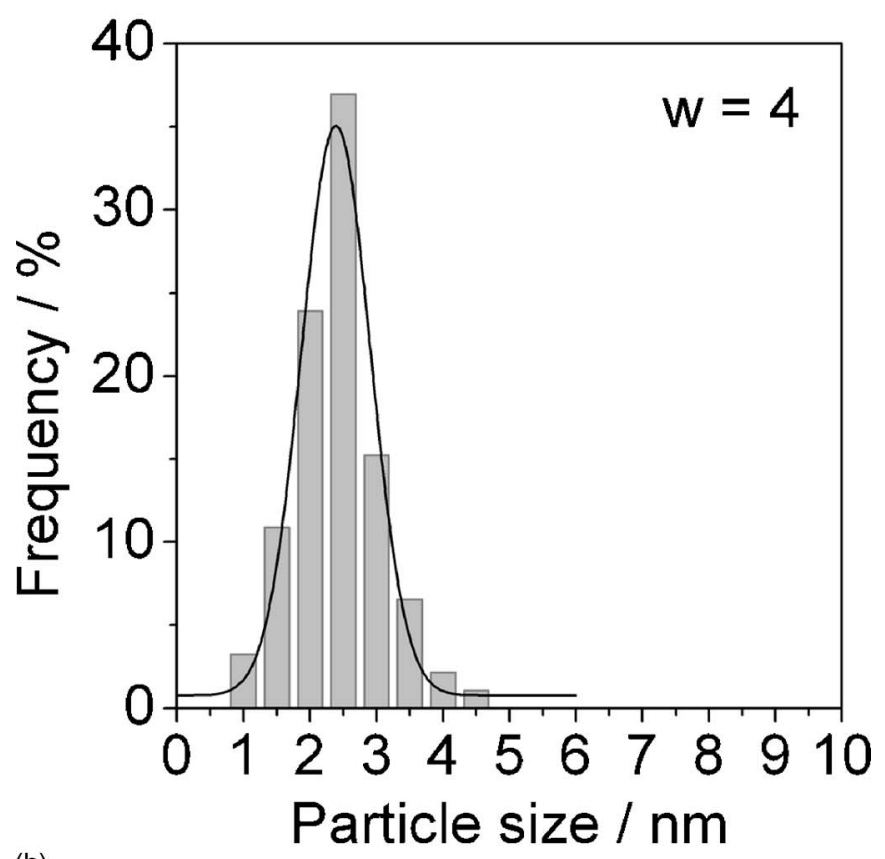

(b)

Figure 2. TEM image of as-prepared Pt-Ru/C catalyst obtained in a microemulsion with $w=4$ and particle size distribution histogram.

Electrochemical behavior and electrocatalytic properties.- The general electrochemical behavior of Pt-Ru/catalysts was examined by $\mathrm{CV}$ in acid solution. The curves obtained for the as-prepared $\mathrm{Pt}-\mathrm{Ru} / \mathrm{C}$ electrocatalysts in $0.5 \mathrm{M} \mathrm{H} \mathrm{H}_{2} \mathrm{SO}_{4}$ acid solution at $50 \mathrm{mV} \mathrm{s}^{-1}$ in the potential range of $0.05-0.8 \mathrm{~V}$ are shown in Fig. 4. Even though all electrodes contained the same amount of metals $\left(28 \mu \mathrm{g} \mathrm{cm}^{-2}\right)$ and the general features of the voltammetric curves are similar, the curve for the catalysts prepared with $w=4$ involves

\begin{tabular}{|c|c|c|c|}
\hline $\mathrm{H}_{2} \mathrm{O} /[\mathrm{AOT}](w)$ & TEM particle size $(\mathrm{nm})$ & $a(\AA)$ & $x(\mathrm{Ru})$ \\
\hline 4 & $2.4 \pm 0.1$ & 3.925 & 0.031 \\
\hline 6 & $2.7 \pm 0.1$ & 3.915 & 0.190 \\
\hline 8 & $3.2 \pm 0.1$ & 3.912 & 0.249 \\
\hline 10 & $3.2 \pm 0.2$ & 3.908 & 0.316 \\
\hline
\end{tabular}




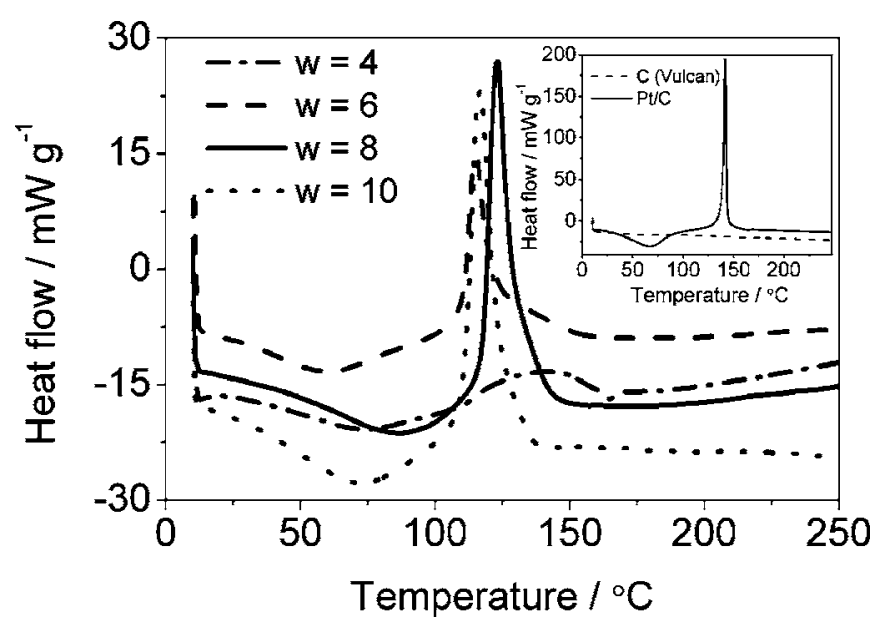

Figure 3. DSC curves taken in flowing $\mathrm{N}_{2}$ for $\mathrm{Pt}-\mathrm{Ru} / \mathrm{C}$ catalysts prepared by a microemulsion method with different values of $w$. Heating rate $5^{\circ} \mathrm{C} \mathrm{min}^{-1}$. Inset: DSC curve for $\mathrm{Pt} / \mathrm{C}$.

significantly smaller currents. For the other three catalysts, it is interesting to note that different ratios between the currents involved in the hydrogen adsorption/desorption region and those measured in the double-layer region are observed. Taking into account DSC results, the differences observed in the $\mathrm{CV}$ are likely to be the result of the different amounts of segregated Ru phases, which could involve metal as well as oxide species.

Figure 5 shows CO stripping voltammograms of the as-prepared $\mathrm{Pt}-\mathrm{Ru} / \mathrm{C}$ catalysts recorded at $5 \mathrm{mV} \mathrm{s}^{-1}$ in the supporting electrolyte, at room temperature. As can be seen, the general shape of the curves, as well as the onset potential of $\mathrm{CO}$ oxidation, change significantly for different catalysts. Only one current peak at $0.75 \mathrm{~V}$ is observed for the $\mathrm{Pt}-\mathrm{Ru} / \mathrm{C}$ catalysts prepared with $w=4$. For the others, a gradual decrease of the current associated to the process occurring at around $0.75 \mathrm{~V}$ is observed for increasing $w$ values, together with a shift toward lower potentials. Simultaneously, another $\mathrm{CO}$ oxidation peak appears at lower potentials, which position shifts from ca. $0.58 \mathrm{~V}$ for the catalysts prepared with $w=6$ to about $0.50 \mathrm{~V}$ for the one prepared with $w=10$.

Besides a recent work in which CO-adsorbed IR spectra were used to characterize the surface structure of unsupported Pt-Ru

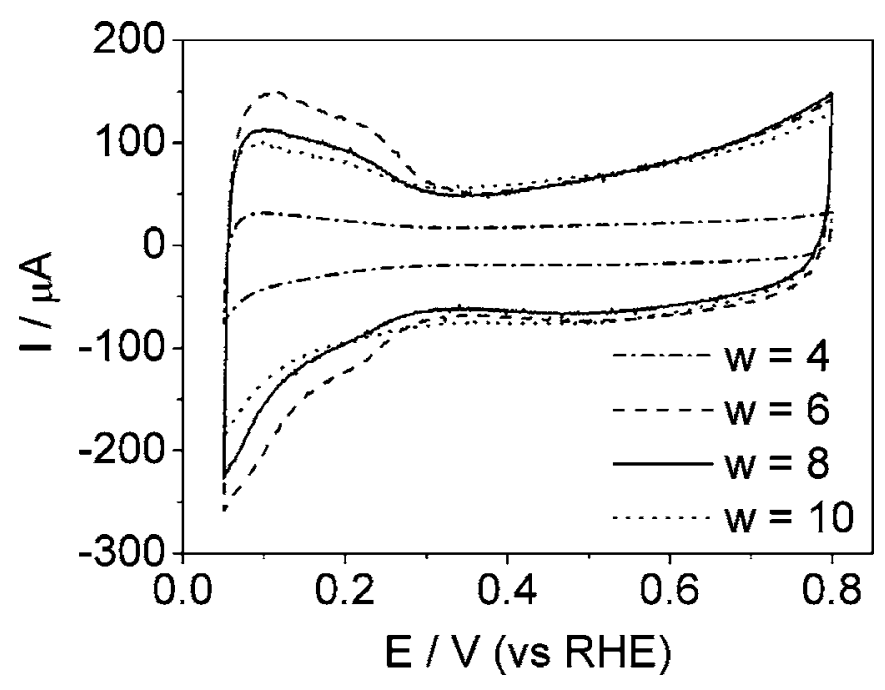

Figure 4. $\mathrm{CV}$ curves of as-prepared $\mathrm{Pt}-\mathrm{Ru} / \mathrm{C}$ catalysts obtained in microemulsion with different values of $w$, as indicated. Electrolyte: $0.5 \mathrm{M} \mathrm{H}_{2} \mathrm{SO}_{4}$. Sweep rate $50 \mathrm{mV} \mathrm{s}^{-1}$.
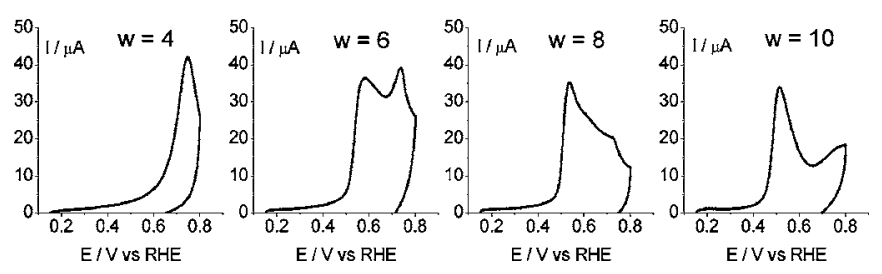

Figure 5. $\mathrm{CV}$ curves for the oxidation of adsorbed $\mathrm{CO}$ on as-prepared $\mathrm{Pt}-\mathrm{Ru} / \mathrm{C}$ catalysts obtained in microemulsion with different values of $w$, as indicated. Sweep rate $5 \mathrm{mV} \mathrm{s}^{-1}$. Electrolyte: $0.5 \mathrm{M} \mathrm{H}_{2} \mathrm{SO}_{4}$.

nanoparticles, ${ }^{32}$ to the best of our knowledge studies of particle size effects on $\mathrm{CO}$ oxidation on Pt-Ru nanoparticles have not been published. However, data available in the literature indicate the existence of the particle size effects for $\mathrm{CO}$ oxidation for Pt nanoparticles, even though some disagreement in the results reported in different works can be found. Arenz et al. ${ }^{33}$ found that the rate of $\mathrm{CO}_{2}$ production was strongly dependent on the particle size, while the onset potential of $\mathrm{CO}$ oxidation was almost the same. In contrast, a shift of onset potential toward more positive values with decreasing particle size has been found by others. ${ }^{34,35}$

Davies et al., ${ }^{36}$ in studies of $\mathrm{CO}$ electro-oxidation on Ru-modified $\operatorname{Pt}(111)$, observed a single sharp oxidation peak at about $0.8 \mathrm{~V}$ for the clean $\mathrm{Pt}(111)$ surface and the appearance of another peak at lower potentials for Ru-modified surfaces. For increasing $\mathrm{Ru}$ coverage the peak at higher potentials decreased and the onset potential of $\mathrm{CO}$ oxidation shifted to lower values. The two processes occurring in different potential regions were considered associated to fast and slow kinetics of the oxidation of $\mathrm{CO}$ taking place through a Langmuir-Hinshelwood $(\mathrm{L}-\mathrm{H})$ mechanism. These two types of $\mathrm{L}-\mathrm{H}$ kinetics were interpreted as being related to $\mathrm{Pt}$ sites neighboring Ru clusters (fast) and to Pt sites which lay at least one atom of Pt away from the Ru sites (slow). In general terms, the curves of Fig. 5 look like those published by Davies et al. ${ }^{36}$

The increase of onset potential of $\mathrm{CO}$ oxidation seen in the curves of Fig. 5 could, in principle, be looked at as following the decrease in particle size. However, the two processes taking place in the low- and high-potential regions follow the variation of $x(\mathrm{Ru})$ and seem to reflect a higher number of Pt sites neighboring Ru sites for larger particles. The curve for the catalyst prepared with $w=4$ suggests that neighboring Pt-Ru sites would be present in very low number for small particles and it is fully consistent with the low value of $x(\mathrm{Ru})$ obtained for this catalyst.

To make a detailed analysis of the mechanistic aspects of the $\mathrm{CO}$ oxidation reaction is actually outside the scope of this work. What really matters to the present study is to show that, despite the fact that all catalysts were prepared in exactly the same way, the variation of just one parameter, i.e., the $w$ value that determines particle size, seems to also produce significant changes of surface properties of the $\mathrm{Pt}-\mathrm{Ru} / \mathrm{C}$ prepared via microemulsion.

Figure 6 shows LSV curves recorded at $50 \mathrm{mV} \mathrm{s}^{-1}$ and the results of chronoamperometric experiments at $0.5 \mathrm{~V}$ for methanol oxidation on the Pt-Ru/C prepared in microemulsions with different $w$. The LSV curves show that the onset potential is, within a few millivolts, about the same for all electrocatalysts. Despite the relatively small differences in particle sizes, the catalyst performances appear significantly different. The catalyst prepared with $w=4$ shows a very poor performance, likely associated to the low value of $x(\mathrm{Ru})$. The catalyst prepared with $w=6$ and 8 exhibit the higher currents, which values are similar up to ca. $0.58 \mathrm{~V}$, potential at which the methanol oxidation current for the former begins to increase faster. Figure $6 \mathrm{~b}$ shows the chronoamperometric curves obtained at $0.5 \mathrm{~V}$. The differences in the electrocatalytic behavior of the as-prepared $\mathrm{Pt}-\mathrm{Ru} / \mathrm{C}$ catalysts are quite marked. In particular, the catalysts obtained in a microemulsion with $w=8$ show larger current values 

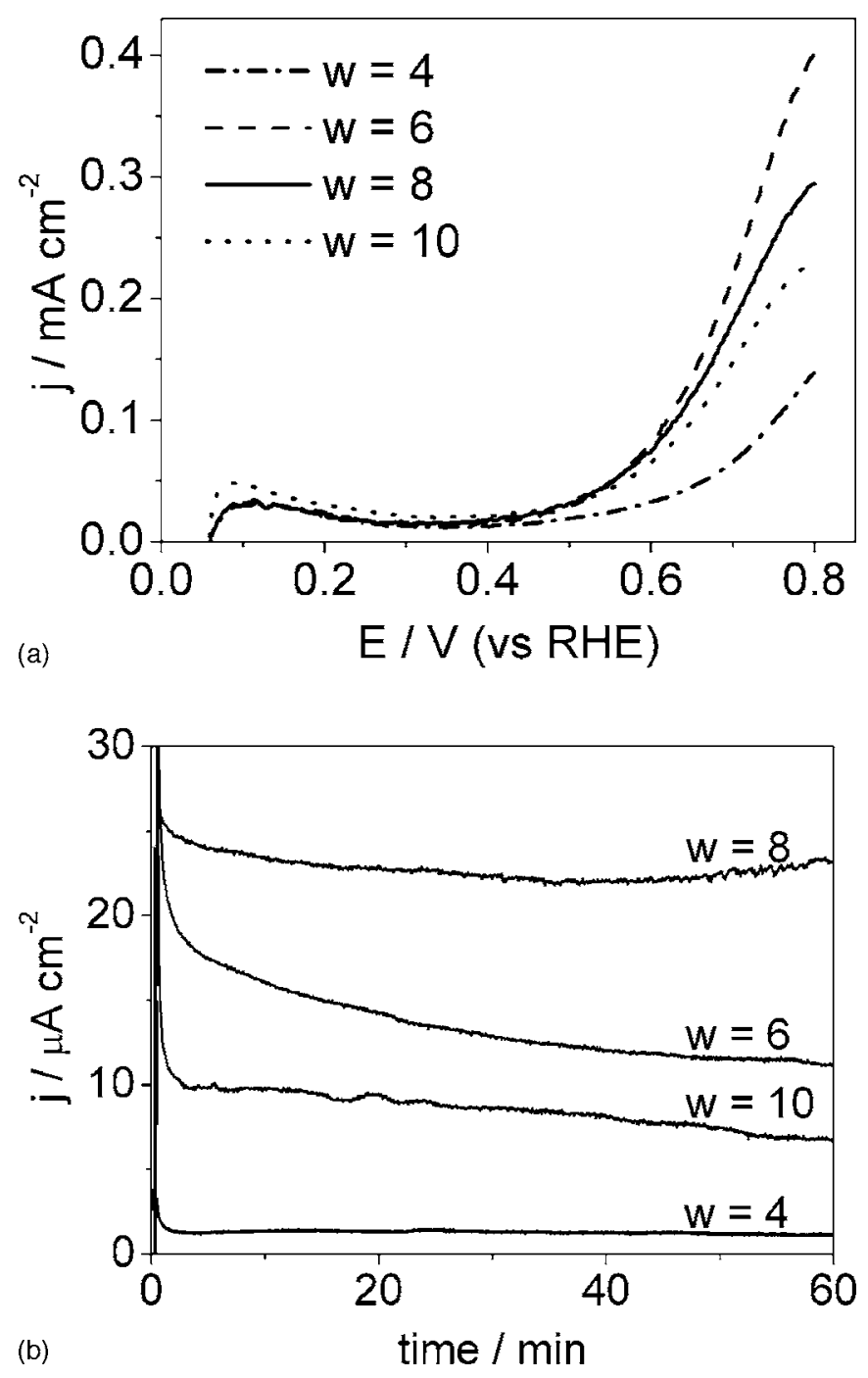

Figure 6. (a) LSV curves for methanol oxidation on as-prepared $\mathrm{Pt}-\mathrm{Ru} / \mathrm{C}$ catalysts obtained in microemulsion with different values of $w$, as indicated. Electrolyte: $0.5 \mathrm{M}$ methanol $+0.5 \mathrm{M} \mathrm{H}_{2} \mathrm{SO}_{4}$. Sweep rate $50 \mathrm{mV} \mathrm{s}^{-1}$. (b) Current-time curves for methanol oxidation obtained at $0.5 \mathrm{~V}$.

and a significantly stable current-time response. Despite the larger value of $x(\mathrm{Ru})$ obtained for the catalysts prepared with $w=10$, its performance is clearly inferior.

In addition, fuel cell polarization curves taken at $90^{\circ} \mathrm{C} / 3$ atm $\mathrm{O}_{2}$ pressure by circulating a $2 \mathrm{~mol} \mathrm{~L}^{-1}$ aqueous methanol solution at the anode (not shown), revealed that the catalyst prepared in a microemulsion with $w=8$ has a performance practically identical to that of a commercial Pt-Ru/C material (E-TEK).

Heat-treated $\mathrm{Pt}-\mathrm{Ru} / \mathrm{C}$ catalysts showed XRD patterns with sharper diffraction signals, consistent with an increase in the mean crystallite size, and larger shifts of the diffraction signals toward higher $2 \theta$ values, indicating an increase in alloying. TEM analysis confirmed that particle growth occurred during heat-treatment, as expected. The increase in the mean particle size was accompanied by an increase in the width of the particle size distribution. In all cases, $\mathrm{CV}$ curves showed a decrease in the currents measured due to the loss of active area produced by particle growth. For all catalysts, a very marked loss of electrocatalytic activity toward methanol oxidation was observed after heat-treatment. This observation is in agreement with results reported for $\mathrm{Pt}-\mathrm{Ru} / \mathrm{C}$ catalysts prepared by a microemulsion method by Xiong and Manthiram. ${ }^{23}$ Figure 7 shows the effect of heat-treatment on the chronoamperometric curves for

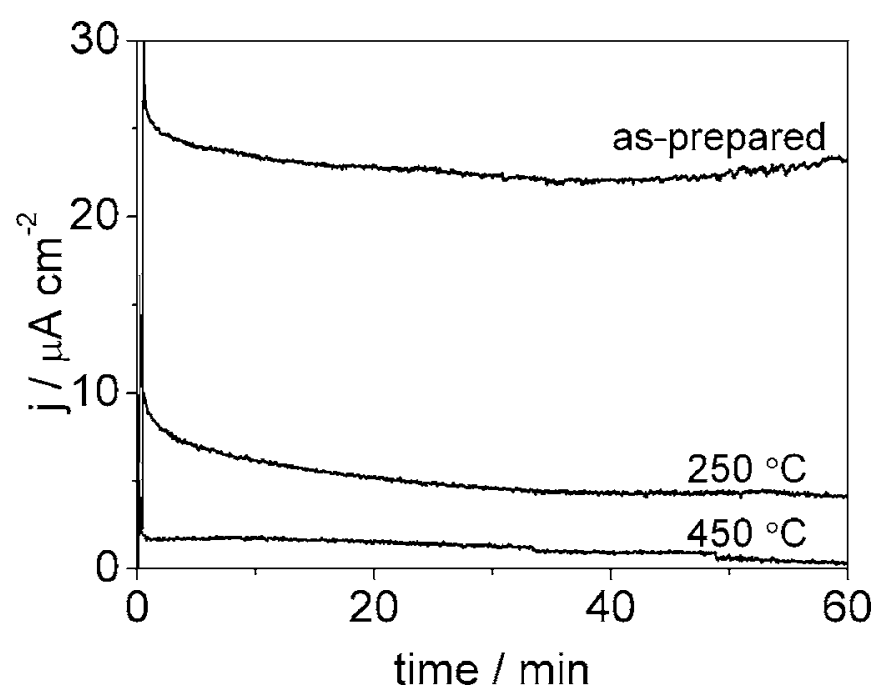

Figure 7. Effect of thermal treatment on the current-time curves for methanol oxidation obtained at $0.5 \mathrm{~V}$ for $\mathrm{Pt}-\mathrm{Ru} / \mathrm{C}$ catalysts prepared in microemulsion with $w=8$. Electrolyte: $0.5 \mathrm{M}$ methanol $+0.5 \mathrm{M} \mathrm{H}_{2} \mathrm{SO}_{4}$.

the $\mathrm{Pt}-\mathrm{Ru} / \mathrm{C}$ catalysts prepared with $w=8$. Considering that the average particle size, as determined from TEM analysis, increases from $3.2 \mathrm{~nm}$ for the as-prepared catalysts to 3.4 and $4.2 \mathrm{~nm}$, for those treated at 250 and $450^{\circ} \mathrm{C}$, respectively, it seems evident that the pronounced decrease on activity produced by heat-treatment greatly exceeded the expected losses associated with loss of active area due to particle growth.

For Pt catalysts, it has been reported that below ca. $5 \mathrm{~nm}$, the specific activity for methanol oxidation decreases with the decrease of Pt particle size. ${ }^{37-39}$ Mukerjee and McBreen studied the role of the geometric parameters and the changes in the electronic structure due to adsorbates on methanol oxidation. ${ }^{40}$ From X-ray absorption spectroscopy (XAS) studies, they concluded that the combined effect of strongly adsorbed $\mathrm{CO}$ and $\mathrm{OH}$ on these small particles inhibits the oxidation of methanol.

Whatever the case, the differences observed in this work for the $\mathrm{Pt}-\mathrm{Ru} / \mathrm{C}$ electrocatalysts prepared in microemulsions seem to largely exceed those expected from particle size varying from ca. 2.5 to $3.5 \mathrm{~nm}$ (see Table I) and evidence that other physical properties of the catalysts have a significant influence on the performance toward methanol oxidation.

It is currently accepted that the function of $\mathrm{Ru}$ is to minimize the effect of the poisonous species through the conversion of $\mathrm{CO}$ to $\mathrm{CO}_{2}$, mainly through a bifunctional mechanism ${ }^{41}$ involving oxygenated species that form at lower potentials than on Pt. However, the nature and role of these oxide species remain unclear. While the formation of ruthenium oxides has been pointed out among the possible causes of the deactivation of Pt-Ru electrocatalysts, ${ }^{42}$ surface $\mathrm{RuO}_{x}$ species are usually observed on $\mathrm{Pt}-\mathrm{Ru} / \mathrm{C}$ anode catalysts by XPS analysis. ${ }^{43}$ TGA and XPS studies performed on Pt-Ru/C commercial catalysts have revealed the presence of substantial amounts of hydrous ruthenium oxide species, ${ }^{43}$ and it was suggested that mixed-phase electrocatalyst containing Pt metal and hydrous ruthenium oxides would have a better electrocatalytic activity than Pt-Ru alloys. ${ }^{31,43}$ In addition, an X-ray absorption near edge spectroscopic (XANES) study of as-prepared Pt-Ru materials showed that Pt and $\mathrm{Ru}$ were predominately in the form of oxides ${ }^{44}$ that were reduced under fuel cell operational conditions. The oxidation of methanol has also been studied on Pt-Ru catalysts prepared at different temperatures between 400 and $600^{\circ} \mathrm{C}$ by the Adams method by Lasch et al. ${ }^{45}$ From XRD and EDX results, these authors claimed that their catalysts contained a Pt-Ru alloy and ruthenium oxides and concluded that both the alloyed metallic Pt-Ru phase as well as the 
amorphous hydrated $\mathrm{Ru}$ oxides would benefit the electrocatalysis of the oxidation reaction. Conversely, Sirk et al. ${ }^{46}$ reported that the performance for methanol oxidation at $25^{\circ} \mathrm{C}$, evaluated by LSV, was better for reduced Pt-Ru commercial catalysts than for as-received and for oxidized samples. Additionally, studies made on Pt nanoparticles dispersed on $\mathrm{RuO}_{2}$ layers showed an enhanced activity for methanol oxidation. 47,48

In general, the performances for methanol oxidation of the $\mathrm{Pt}-\mathrm{Ru} / \mathrm{C}$ catalysts, prepared in this work by a microemulsion method, do not follow the trend of changes in the amount of the $\mathrm{Pt}-\mathrm{Ru}$ alloyed phase. Because TG and DSC measurements indicate that the segregated $\mathrm{Ru}$ is at least partially oxidized, it seems reasonable to conclude that hydrous ruthenium oxides are playing a role in the oxidation of methanol. Also, as the effects of thermal treatment are not limited to particle growth but also involve an increase in alloying and the reduction of oxide species, the pronounced loss of activity observed for heat-treated catalysts could then be interpreted as related to the removal of hydrous oxides from the catalyst surface. Thus, it seems likely that besides any effect that particle size may have on the catalytic activity for methanol oxidation, the significant differences in the behavior of the $\mathrm{Pt}-\mathrm{Ru} / \mathrm{C}$ prepared in this work may also be associated with the combined effects of different amounts of a Pt-Ru alloyed phase and hydrous ruthenium oxides.

All together, the results obtained in this work demonstrate that the variation of particle size of $\mathrm{Pt}-\mathrm{Ru} / \mathrm{C}$ catalysts produced changes in other properties that also contribute to determine the electrocatalytic activity toward methanol oxidation, contributions which cannot be separated. Thus, to establish correlations between electrocatalytic activity for methanol oxidation and particle size of $\mathrm{Pt}-\mathrm{Ru} / \mathrm{C}$ catalysts remains a difficult task.

\section{Conclusions}

$\mathrm{PtRu} / \mathrm{C}$ nanocatalysts were prepared by a microemulsion method using different values of water/surfactant molar ratio to obtain catalysts with different particle sizes and narrow distribution. This study demonstrates that even though the particle size could be varied as expected for the method used to synthesize the catalysts, other properties, such as lattice parameter and amounts of alloyed $\mathrm{Ru}$ and oxides, change as well. All these properties seem to simultaneously contribute to the electrocatalytic activity and, therefore, attention should be paid to the fact that attempting to make direct correlations between electrochemical performance and particle size for $\mathrm{Pt}-\mathrm{Ru} / \mathrm{C}$ catalysts demands caution, because the effects of other relevant parameters cannot be neglected.

\section{Acknowledgments}

Thanks are due to the Brazilian Agencies Fundação de Amparo à Pesquisa do Estado de São Paulo (FAPESP, Proc. 04/15570-8) and Conselho Nacional de Desenvolvimento Cientifico e Tecnológico (CNPq, Proc. 550153/2005-5), and to the PROCAC Program for financial support. D.R.M.G. thanks PROCAC for a fellowship. We also thank Dr. Elisabete I. Santiago (PROCEL/IPEN-CNEN/SP) for the fuel cell measurements.

FAPESP assisted in meeting the publication costs of this article.

\section{References}

1. M. Watanabe, M. Uchida, and S. Motoo, J. Electroanal. Chem. Interfacial Electrochem., 229, 395 (1987)

2. V. Radmilovic, H. A. Gasteiger, and P. N. Ross, Jr., J. Catal., 154, 98 (1995)

3. S. Alerasool and R. D. Gonzalez, J. Catal., 124, 204 (1990).

4. H. Bonnemann, R. Brinkmann, W. Brijoux, E. Dinjus, T. Joussen, and B. Korall, Angew. Chem., Int. Ed. Engl, 30, 804 (1991).

5. E. R. Gonzalez, E. A. Ticianelli, A. L. N. Pinheiro, and J. Perez, Brazilian Pat.,
INPI-SP No. 00321 (1997)

6. J. B. Goodenough, A. Hamnett, B. J. Kennedy, R. Manoharan, and S. A. Weeks, Electrochim. Acta, 35, 199 (1990).

7. E. Antolini, Mater. Chem. Phys., 78, 563 (2003).

8. A. J. Dickinson, L. P. L. Carrette, J. A. Collins, K. A. Friedrich, and U. Slimming, Electrochim. Acta, 47, 3733 (2002).

9. B. Yang, Q. Lu, Y. Wang, L. Zhuang, J. Lu, and P. Liu, Chem. Mater, 15, 3552 (2003).

10. D. C. Azevedo, W. H. Lizcano-Valbuena, and E. R. Gonzalez, J. New Mater. Electrochem. Syst., 7, 191 (2004).

11. J. W. Guo, T. S. Zhao, J. Prabhuram, R. Chen, and C. W. Wong, Electrochim. Acta, 51, 754 (2005).

12. S.-Y. Huang, S.-M. Chang, and C.-T. Yeh, J. Phys. Chem. B, 110, 234 (2006)

13. L. dos Santos, F. Colmati, and E. R. Gonzalez, J. Power Sources, 159, 869 (2006)

14. M. Carmo, V. A. Paganin, J. M. Rosolen, and E. R. Gonzalez, J. Power Sources, 142, 169 (2005)

15. C. W. Hills, N. H. Mack, and R. G. Nuzzo, J. Phys. Chem. B, 107, 2626 (2003).

16. J. L. Gómez de la Fuente, M. V. Martinez-Huerta, S. Rojas, P. Terreros, J. L. G Fierro, and M. A. Peña, Catal. Today, 116, 422 (2006)

17. I. Capek, Adv. Colloid Interface Sci., 110, 49 (2004).

18. D. E. Ganguli and M. Ganguli, Inorganic Particle Synthesis via Macro- and Microemulsions: A Micrometer to Nanometer Landscape, pp. 99-102, Kluwer, New York (2003).

19. Z. Liu, J. Y. Lee, M. Han, W. Chen, and L. M. Gan, J. Mater. Chem., 12, 2453 (2002)

20. Y. Liu, X. Qiu, Z. Chen, and W. Zhu, Electrochem. Commun., 4, 550 (2002).

21. X. Zang and K.-Y. Cahn, Chem. Mater, 15, 451 (2003).

22. J. Solla-Gullón, F. J. Vidal-lglesias, V. Montiel, and A. Aldaz, Electrochim. Acta, 49, 5079 (2004).

23. L. Xiong and A. Manthiram, Solid State Ionics, 176, 385 (2005).

24. S. Rojas, F. J. García-García, S. Jaras, M. V. Martínez-Huerta, J. L. García Fierro, and M. Boutonnet, Appl. Catal., A, 285, 24 (2005).

25. J. Schmidt, H. A. Gasteiger, G. D. Stab, P. M. Urban, D. M. Kolb, and R. J. Behm, J. Electrochem. Soc., 145, 2354 (1998).

26. V. A. Paganin, E. A. Ticianelli, and E. R. Gonzalez, J. Appl. Electrochem., 26, 297 (1996).

27. O. A. Baturina, S. R. Aubuchon, and K. J. Wynne, Chem. Mater, 18, 1498 (2006)

28. A. S. Arico, P. Creti, H. Kim, R. Mantegna, N. Giordano, and V. Antonucci, J. Electrochem. Soc., 143, 3950 (1996).

29. Pearson's Handbook of Crystallographic Data for Intermetallic Phase, P. Villars and L. D. Calvert, Editors, p. 3046, American Society for Metals, Metals Park, OH (1985)

30. B. C. Beard and P. N. Ross, J. Electrochem. Soc., 137, 3368 (1990)

31. D. R. Rolison, P. L. Hagans, K. E. Swider, and J. W. Long, Langmuir, 15, 774 (1999).

32. A. Baranova, C. Bock, D. Ilin, D. Wang, and B. MacDougall, Surf. Sci., 600, 3502 (2006).

33. M. Arenz, K. J. J. Mayrhofer, V. Stamenkovic, B. B. Blizanac, T. Tomoyuki, P. N. Ross, and N. M. Markovic, J. Am. Chem. Soc., 127, 6819 (2005).

34. S. Park, X. Yong, and M. Weaver, Langmuir, 18, 5792 (2002).

35. O. V. Cherstiouk, P. A. Simonov, and E. R. Savinova, Electrochim. Acta, 48, 3851 (2003)

36. J. C. Davies, B. E. Hayden, D. J. Pegg, and M. E. Rendall, Surf. Sci., 496, 110 (2002)

37. A. Kabbabi, F. Gloagen, F. Andolfatto, and R. Durand, J. Electroanal. Chem., 373 , 251 (1994)

38. T. Frelink, W. Visscher, and J. A. R. van Veen, J. Electroanal. Chem., 382, 65 (1995)

39. Y. Takasu, T. Iwazaki, W. Sugimoto, and Y. Murakami, Electrochem. Commun., 2, $671(2000)$

40. S. Mukerjee and J. McBreen, J. Electroanal. Chem., 448, 163 (1998).

41. M. Watanabe and S. Motoo, J. Electroanal. Chem. Interfacial Electrochem., 60, 267 (1975)

42. H. Hoster, T. Iwasita, H. Baumgartner, and W. Vielstich, Phys. Chem. Chem. Phys., 3, 337 (2001).

43. J. W. Long, R. M. Stroud, K. E. Swider-Lyons, and D. R. Rolison, J. Phys. Chem $B, \mathbf{1 0 4}, 9772$ (2001).

44. W. E. O'Grady, P. L. Hagans, K. I. Pandya, and D. L. Maricle, Langmuir, 17, 3047 (2001)

45. K. Lasch, L. Jorissen, K. A. Friedrich, and J. Garche, J. Solid State Electrochem., 7, 619 (2003)

46. A. H. C. Sirk, J. M. Hill, S. K. Y. Kung, and V. I. Birss, J. Phys. Chem. B, 108, 689 (2004).

47. H. M. Villullas, F. I. Mattos-Costa, and L. O. S. Bulhões, J. Phys. Chem. B, 108 , 12898 (2004).

48. H. M. Villullas, F. I. Mattos-Costa, P. A. P. Nascente, and L. O. S. Bulhões, Chem Mater, 18, 5563 (2006) 